Portland State University

PDXScholar

1990

\title{
An evaluation of the academic success of students who participated in the English for non-native residents program at Portland State University
}

Linda Carol Andrews Dunn

Portland State University

Follow this and additional works at: https://pdxscholar.library.pdx.edu/open_access_etds

Part of the Applied Linguistics Commons, and the Bilingual, Multilingual, and Multicultural Education Commons

Let us know how access to this document benefits you.

\section{Recommended Citation}

Dunn, Linda Carol Andrews, "An evaluation of the academic success of students who participated in the English for non-native residents program at Portland State University" (1990). Dissertations and Theses. Paper 3969.

https://doi.org/10.15760/etd.5853

This Thesis is brought to you for free and open access. It has been accepted for inclusion in Dissertations and Theses by an authorized administrator of PDXScholar. Please contact us if we can make this document more accessible: pdxscholar@pdx.edu. 
AN ABSTRACT OF THE THESIS OF Linda Carol Andrews Dunn for the Master of Arts in TESOL presented June 4, 1990.

Title: An Evaluation of the Academic Success of Students who Participated in the English for Non-native Residents Program at Portland state University.

APPROVED BY THE MEMBERS OF THE THESIS COMMITTEE:

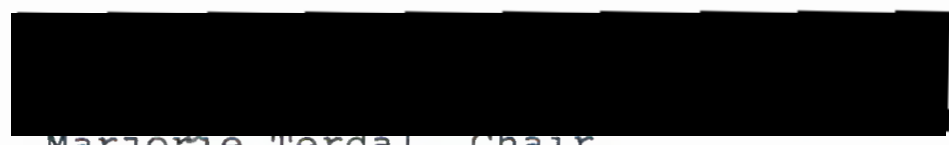

Marjorie rerdal, chair
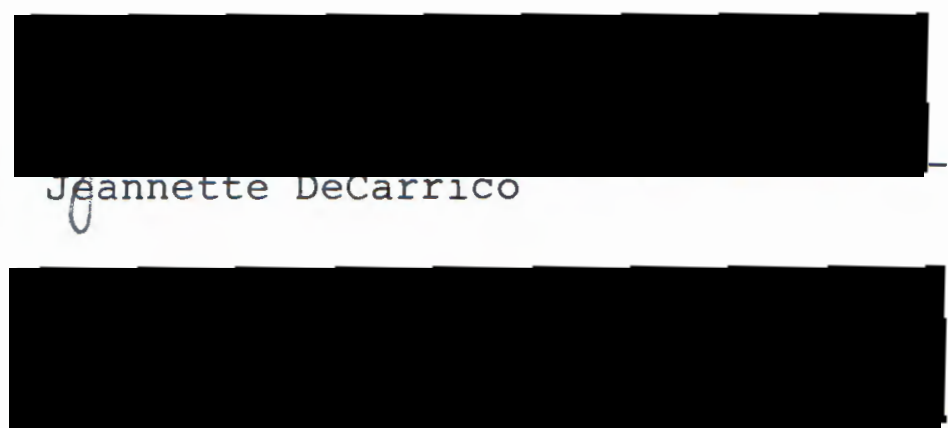

Devorah Lleberman

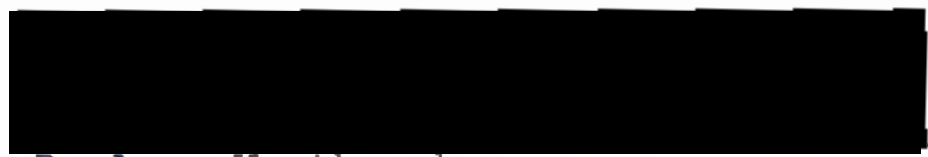

DeeAnne Westbrook

Many programs exist across the United States to prepare non-native English speaking students for academic work. The effectiveness of these programs has been the subject of various research projects, with mixed results. Some 
have found that the programs they have examined seem to have led to higher achievement among participants. Others have found that it is difficult to show any effect. However, the amount of time and resources devoted to such programs warrants continuing efforts to evaluate their success.

This study compares the academic records of non-native English speaking students who were enrolled in the English for Non-native Residents Program (ENNR) at Portland state University (PSU) with those of a group of similar students who did not enroll in the program, with the goal of answering the following questions: (1) Does enrollment in the ENNR program have a positive effect on academic performance at PSU? (2) Does enrollment in the ENNR program have a positive effect on performance in composition classes? (3) Does enrollment in the ENNR grammar workshop have a positive effect on performance in the basic composition course? (4) Does enrollment in the ENNR program have a positive effect on performance in PSU courses requiring relatively more reading?

The academic records of 274 students were examined in the study. The subjects consisted of ENNR participants who enrolled in the program in $1984,1985,1986$, and 1987 and a control group of similar students not enrolled in the program. The data gathered consisted of cumulative GPA, credit hours earned per term enrolled, grades in two composition courses, credit hours and grades earned in 
courses requiring relatively more reading (such as social science and humanities), number of students academically disqualified, and number of students who earned bachelor's degrees after at least four years of study.

No significant differences were found between the treatment groups and the control group on any measures except one: more students in the control group earned bachelor's degrees. Confounding factors prevent the researcher from concluding that this study shows no significant effect of the ENNR program on students' academic achievement. Unknown variables among the subjects, a control group not ideally matched in English ability to the test group, and the elusiveness of the connection between language ability and academic success argue against concluding that the ENNR program does not improve students' ability to succeed at PSU. In fact, it can be concluded that the lack of difference between the two groups shows that the ENNR program is helping a problematic student group to compete successfully at PSU. 
AN EVALUATION OF THE ACADEMIC SUCCESS OF STUDENTS WHO PARTICIPATED IN THE ENGLISH FOR NON-NATIVE RESIDENTS PROGRAM AT PORTLAND STATE UNIVERSITY

by

LINDA CAROL ANDREWS DUNN

A thesis submitted in partial fulfillment of the requirements for the degree of

\section{MASTER OF ARTS}

in

TESOL

Portland State University

1990 
TO THE OFFICE OF GRADUATE STUDIES:

The members of the Committee approve the thesis of

Linda Carol Andrews Dunn presented June 4, 1990.

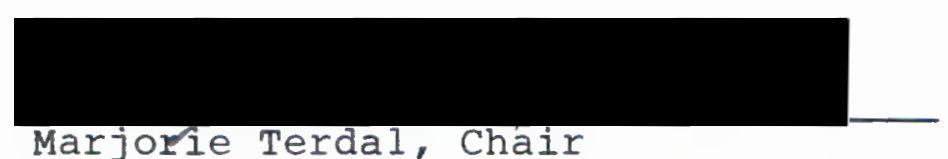

Marjorie Teral, Chair
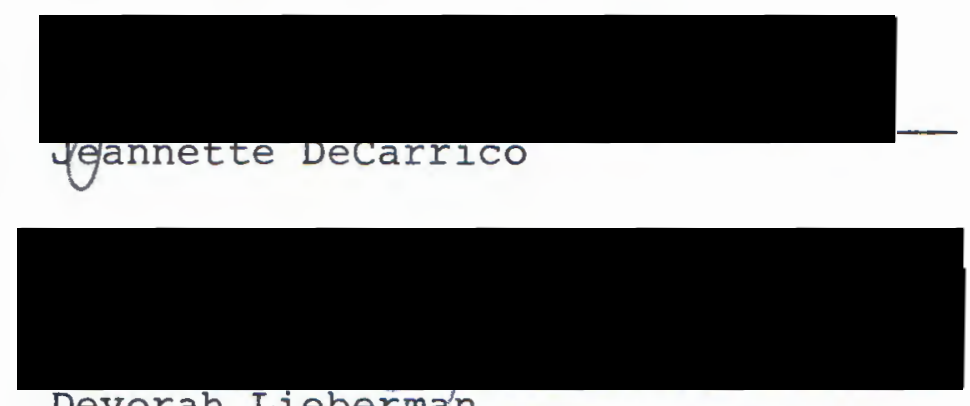

Devorah Lieberman

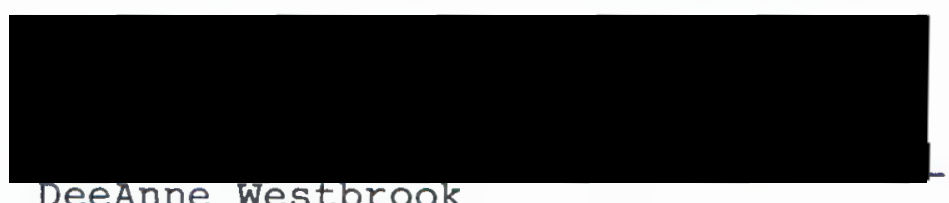

DeeAnne westbrook

\section{APPROVED :}

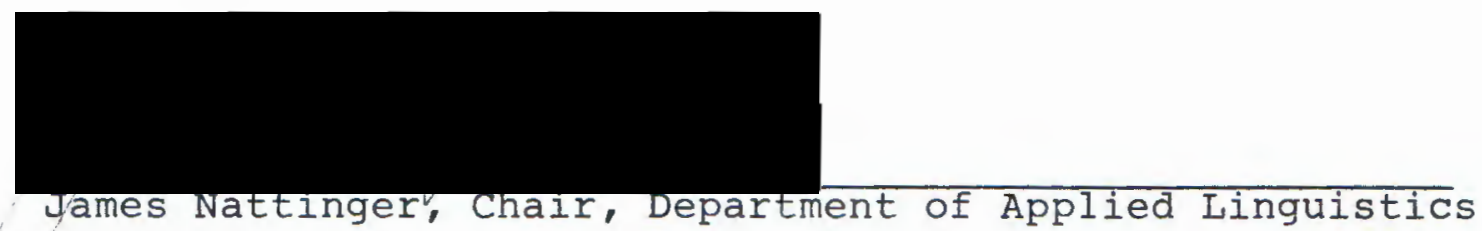

c. William savery, Inter $m$ vice provost for Graduate studies and Research 


\section{ACKNOWLEDGEMENTS}

I gratefully acknowledge those who gave their valuable time and resources in support of this project: my advisor, Dr. Marjorie Terdal; the members of my committee, Dr. Jeannette DeCarrico, Dr. Devorah Lieberman, and Dr. DeeAnne Westbrook; my father, Dr. Fred C. Andrews, Professor Emeritus of Mathematics at the University of oregon, who provided statistical assistance; and my husband, Pierre G. Dunn, without whose unfailing support I could not have completed this thesis. 
TABLE OF CONTENTS

PAGE

ACKNOWLEDGEMENTS

CHAPTER

I INTRODUCTION . . . . . . .

A Description of the ENNR Program . . . . .

Summary . . . . . . . . 4

I I REVIEW OF THE LITERATURE . • •

Skills Necessary for

Academic Success . . . 6

GPA as a Measure of Academic Success . .

Evaluation of Basic

English Programs . .

II I METHODS AND PROCEDURES . . . .

Subjects . . . . . . . 21

Analysis of the Data . . . 24

Academic Success . . .

Performance in WR 121 and WR 323 .....

The Effect of the ENNR Grammar Workshop . . 
Performance in Courses

Requiring More Reading 36

V CONCLUSION AND DISCUSSION . . . 40

Limitations . . . . . . 42

Implications . . . . . 47

REFERENCES • • • • • • • • • • • • • 53 
LIST OF TABLES

TABLE

PAGE

I Cumulative GPAS . . . . . . .

II Anova for Cumulative GPA . . . .

II Credit Hours Earned per Term of Enrollment . . . . . . .

IV Anova for Mean Credit Hours per Term . . . . . . . . .

V Credit Hours Earned per Term Groups 1 \& 4 . . . . . . . . .

VI Credit Hours Earned per Term Groups 1 \& 5 . . . . . . .

VII Number Academically Disqualified .

VIII Bachelor's Degrees Earned . . .

IX Grades in WR 121 and WR 323 . . •

$\mathrm{X}$ Number of Subjects Who Repeated WR 121 or WR 323 . • . . • •

XI Performance in Wr 121 of Grammar Workshop Participants . . . .

XII Credits in Courses Requiring Reading, Per Term Enrolled . .

XIII Anova for Mean Credit Hours Requiring Reading . . . . . .

XIV Credits with Grade $\mathrm{C}$ or Better in Courses Requiring Reading, per Term Enrolled . . . . . .

XV Anova for Credits with Grade C or Better in Courses Requiring Reading per Term Enrolled 
vii

XVI Graduation Rates for First-Time

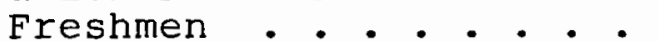




\section{CHAPTER I}

\section{INTRODUCTION}

The English for Non-Native Residents (ENNR) program at Portland State University (PSU) is a semi-intensive course of study designed to help non-native students with limited English proficiency make the transition from high school or community college to university work. This program has been operating at PSU for nearly five years. During that time, instructors in the program have raised questions about its effectiveness. Does the program really help students prepare for university work? Are they able to succeed in the required freshman composition course, WR 121, after completing the advanced ENNR course? Do these students benefit from the direct and intensive grammar instruction provided in the ENNR program's grammar workshop?

In response to these concerns, this study was undertaken to compare the academic records of students who enrolled in the ENNR program from fall term 1984 through fall 1989 with the academic records of a control group of similar students, with the goal of testing the following hypotheses:

1. Enrollment in the ENNR program has a positive effect on academic performance at Portland state 
University, as measured by significantly higher cumulative grade point averages, higher number of credit hours earned per term of enrollment, fewer students being academically disqualified, and more students receiving a bachelor's degree after at least four years of study, among ENNR students as compared to the control group.

2. Enrollment in the ENNR program has a positive effect on performance in WR 121 and WR 323 as measured by a significantly higher number of ENNR students receiving at least a C grade in WR 121 and WR 323 as compared to the control group.

3. Enrollment in the ENNR grammar workshop has a positive effect on performance in WR 121, as measured by a significantly higher number of grammar workshop participants receiving at least a C grade in WR 121 as compared to the control group.

4. Enrollment in the ENNR program has a positive effect on performance in academic courses requiring relatively more reading (such as social science and humanities) as measured by a significantly higher number of credit hours attempted in those subjects per term enrolled and a significantly higher number of credit hours with grades of $\mathrm{C}$ or better in those subjects per term enrolled, among ENNR participants as compared to the control group. 
A DESCRIPTION OF THE ENNR PROGRAM

The ENNR program at PSU was begun in 1984 to meet the needs of legal residents of the United States, entering PSU, who needed additional instruction in English as a second language while taking other academic courses. Only non-native resident freshmen and sophomores are eligible for the ENNR program; international students in the United States on student visas are not eligible. ENNR students are primarily Southeast Asian refugees and many have been in the United States for more than a year. Some of them arrived when they were children and attended American public schools. Others are new to the United States.

Reading and writing classes are offered at three levels in the ENNR program: lower intermediate, intermediate, and advanced. Placement in these levels is based on scores on the Michigan Test of English Language Proficiency and the Comprehensive English Language Test for Speakers of English as a Second Language (CELT), and on a writing sample. Students normally enroll for six credit hours of writing/reading instruction. A non-credit, two-hour course in listening comprehension and note taking practice is required for students whose CELT scores fall below 90. A grammar workshop is required for students whose English proficiency is especially low. This class is a two-hour course designed to target each student's problem areas, and it is expanded to four hours for one term each year to help 
extremely low proficiency students. Students required to take the grammar workshop are those among the ENNR students whose English is the most limited. ENNR students may also enroll for up to 15 credit hours of other academic classes of their own choosing. Students who successfully complete the advanced level are eligible to enroll in the composition course required of all PSU students, WR 121, despite low Scholastic Aptitude Test (SAT) and/or Test of Standard Written English (TSWE) scores.

The ENNR program also provides advising and tutoring services. All students are given help in making their first appointment with an academic advisor in their major field and help in preparing for the meeting. In addition, all ENNR students are assigned an experienced ENNR advisor who provides general advice and counseling. Tutors are provided for those who show a special need for such help or who request it.

SUMMARY

This study examined the academic records of students in the ENNR program from 1984-1987 and, using various criteria, compared their achievement to that of a control group consisting of non-native English speakers who were not enrolled in the program. The groups were compared on the basis of credit hours earned, grade point averages, number of bachelor's degrees, number of academic disqualifications, 
success in WR 121, and success in courses requiring relatively more reading. 


\section{CHAPTER I I}

\section{REVIEW OF THE IITERATURE}

A review of relevant literature was conducted to determine what other researchers have found regarding three pertinent areas of investigation: 1) what English skills are necessary for academic success, 2) is GPA a valid measure of academic success, and 3) what have been the results of evaluations of "remedial"* English and English as a second language programs?

\section{SKILIS NECESSARY FOR ACADEMIC SUCCESS}

In order to develop a curriculum that will help non-native English speakers to develop the language skills they need to succeed in college classes, it is necessary to establish which skilis are the most important for students. Unfortunately, research in this area is not conclusive and the findings vary according to the research method used and who the subjects are. Nevertheless, some

*Some of the studies cited below use the term "remedial" in referring to ESL programs. I do not consider ESI programs to be remedial, since they are comparable to any other foreign language instruction; they are teaching a second language, not attempting to compensate for inadequate native language abilities. However, I have not changed the usage of the term "remedial" by the researchers I have cited. 
studies are enlightening.

Ann Johns (1981) conducted a study at San Diego state University in which ten percent of the faculty (200 people) were questioned about what skills they thought were most important to success in their classes. The respondents were asked to focus on one of the classes they taught and to rank English skills for that class in order of importance.

Johns found that over fifty percent of the faculty listed reading as the most important skill. Only in the English-related departments was writing considered more important than reading. Faculty from the arts, business, physical education, and physical and social sciences ranked listening as first in importance at a rate of over fifty percent. Taking all the respondents together, Johns found the following ranking of skills in order of importance: reading, listening, writing, and speaking.

Johns concluded that teachers who prepare ESI students for academic work should teach reading skills using real texts and problems from academic English. Systematic teaching of listening and note-taking skills should be an important part of all classes and, she stated, writing and speaking should be secondary to reading and listening activities. She suggested that when writing is taught, it should involve the paraphrasing or summarizing of reading materials or the organizing and rewriting of lecture notes. Johns' findings largely support those of Ostler (1980) 
who questioned students rather than faculty at the American Language Institute (ALI) at the university of Southern California. ALI's advanced classes have traditionally focused on writing skills but teachers had sensed for some time that their students' real needs were not being met. Student dissatisfaction led to the development of a questionnaire that was distributed to ALI students. It consisted of fifty-six questions on biographical material and self-evaluation; it also included sentence-combining and paragraph summary tasks so that the students' skills could be evaluated.

The respondents indicated that their greatest needs were the abilities to read textbooks (ninety percent), take notes in class (eighty-four percent), and ask questions in class (sixty-eight percent). Writing research papers was seen as important by fifty-eight percent. The students, then, agreed with the faculty in Johns' study, reporting that reading and listening are the most necessary academic skills.

Christison and Krahnke (1986) obtained similar results when they surveyed non-native English speaking students at five other universities regarding which English skills they use in academic classes. After conducting open-ended interviews with a structured set of topics, they report that most students found the skills of listening and reading to be more useful in university work than those of writing and 
speaking. In fact, many who had difficulty with listening compensated for it by relying more on reading.

All of the studies cited above concluded that reading is the most important skill contributing to academic success. It is for this reason that one question being investigated in this present study is how well ENNR students do in classes that require relatively more reading than other classes.

GPA AS A MEASURE OF ACADEMIC SUCCESS

When attempting to determine the level of a student's academic success, the most obvious measure to look at is the grade point average. Many researchers have used GPA in correlational and predictive studies of the academic achievement of international students. Sugimoto (1966) studied over 2,000 international students at the university of California at Los Angeles and found that their first semester GPAs were the best index of the student's eventual success. Martin (1977) used first and second semester GPA as a measure of international students' academic success at the University of North Carolina at Chapel Hill. Sokari (1980) used cumulative GPA as a measure of achievement in his predictive study of international students at two private religious universities.

Eliason and Jenkins (1990) also used GPA to investigate the relationship between language proficiency and academic 
success. However, they looked at two other measures:

percentage of bad grades and percentage of "problem credits" as additional evidence of success or lack of success. Their justification for looking beyond GPA was the limitations other researchers have noted as to what can be said about a student's academic career by looking at GPA alone. As Heil and Aleamoni (1974) pointed out, "the GPA for one student may be based on four courses, whereas another student's may be based on six courses. . . The majority of international students carry light course loads because they must enroll in remedial English courses" (p. 3). Courses also vary greatly in difficulty and content as Ho and spinks (1985) argued. They also pointed out that "various academic subjects demand divergent competencies or dispositions" ( $p$. 258) .

Therefore, other criteria should also be used to determine how successful a student has been in his/her college career. How many credit hours did the student carry per term? What kind of classes did the student take? Did the student succeed in earning a degree? In the present study, GPA was not the only measure used to determine academic success. Total credit hours, number of credit hours per term of enrollment, grades in courses requiring more reading, and whether the student graduated were also used to show students' levels of achievement. 
EVALUATION OF BASIC ENGLISH PROGRAMS

Across the country there are many English and ESL programs at colleges and universities that are designed to bring entering students' English skills up to the level necessary for academic success. Only a few of these programs have undergone evaluation to determine whether they are meeting their goals. Such studies have produced mixed results.

An ESL program at the University of Hawaii was studied by Mason (1971), who found that an intensive course of study at the University's English Language Institute did not improve students' test scores enough to exempt them from ESI work. The students, whose English had been tested in the areas of writing, reading, aural comprehension, and English structure upon entrance to the University, were given at least seven courses in English tailored to their individual needs. Nearly identical tests were administered after the period of study. It was found that, although they had made significant improvement in all areas except aural comprehension, their test scores were still low enough to require them to repeat some of the ESL courses. These results led Mason to question the value of prescribing compulsory ESL work on the basis of test battery scores. However, more relevant to a study of the ENNR program at P.S.U. is Mason's additional conclusion that allowing international students to enter the second language 
environment through full participation in the regular university program may be more pedagogically sound and economically advantageous. Since P.S.U.'s program does allow students to take regular classes where they are exposed to real use of English, it is interesting to look at ENNR students' progress in light of Mason's work.

Findings related to Mason's were reported by Mosback (1977). His work was done at the University of Addis Ababa, Ethiopia, where, although the larger environment is non-English speaking, many courses are taught in English due to the availability of teachers and materials. This necessitates a level of English ability for students that is comparable to the level needed by international students studying in the U.S., at least in terms of the academic use of English. The University of Addis Ababa provided, at the time of Mosback's study, general backup courses in service English consisting of three hours of instruction per week, with pre- and post-testing. In comparing scores on these tests, Mosback found a mean overall improvement of only 0.9 percent.

Mosback concluded that service English courses are largely a waste of resources. As a result, the University of Addis Ababa decided to restructure the English program and provide small-group courses catering to specific, clearly defined needs, such as English for science. In other words, the English courses would become an integral 
and relevant part of the students' regular university course work.

The question of whether students show significant improvement after developmental ESI courses was also addressed by Brown (1980) at the University of California at Los Angeles. His study is particularly interesting because he looked at the grades in an advanced ESL course as well as test scores and compared two different groups of students. Brown was interested in how students who worked their way up through lower and intermediate ESL courses to an advanced course (continuing subjects) would compare with students who, on the basis of proficiency test scores, were placed directly into the advanced course (placed subjects). He gathered his data during three consecutive quarters, fall, winter, and spring of 1978, and his subjects consisted of 201 placed students and 118 continuing students. Brown's comparisons were based on the students' grades in the advanced course, their scores on the departmental final exam, and their scores on a fifty-item cloze test.

As Brown hypothesized, he found a significant

difference between the two groups of students on all three measures. During the entire school year, the placed subjects had a higher mean GPA than the continuing subjects. The placed subjects also scored higher on the final examination and higher on the cloze test. While realizing the need for further research on this question, Brown 
suggested several variables that may have affected his results. These include the timing and nature of the placed subjects' previous English study and possible differences in ability to learn English between the two groups. A pre- and post-test research design might help to explain the differences between the groups. However, Brown also pointed out that the lower level ESI classes taken by the continuing subjects may not have been adequate to bring them up to the level of other advanced students.

In discussing the success of ESL programs in preparing students for academic work, it is important to note that students with limited English proficiency (LEP) may require more time than they are usually allowed to bring their skills up to the level necessary for competing with other students. Collier (1987) analyzed the length of time necessary for elementary school age and high school age LEP students to become proficient in English for academic purposes while attending classes in all subject areas in English. She compared these students' scores on the science Associates Tests in reading, language arts, mathematics, science, and social studies with the scores of native English speaking students. Her results indicated that the LEP students who began an ESL program at ages 8 to 11 required 2 to 5 years to achieve the 50 th percentile on the tests. Students who began at ages 12 to 15 had the most difficulty catching up with native speakers; Collier 
projected that they would require 6 to 8 years to reach grade level. The explanation that she offered for the greater difficulty of older students is that secondary schools put greater demands on students and that the older students have even less time in which to reach the level of native speakers.

In a later work, Collier (1989) synthesized available research on the question of how long it takes LEP students to reach the grade level of their non-LEP peers in both bilingual and monolingual school situations and made the following conclusions: (1) Students who are provided solid academic instruction in both first and second languages "generally take from 4 to 7 years to reach national norms on standardized tests in reading, social studies, and science (measures of thinking skills)" (p. 526), while they may take as little as 2 years in the areas of mathematics and language arts (speling, punctuation, and simple grammar). (2) Students who are taught exclusively in the second language take 5 to 7 years to reach grade level norms on these tests. (3) "Consistent, uninterrupted cognitive academic development in all subjects throughout students' schooling is more important than the number of hours of second language instruction for successful academic achievement in a second language" (p. 527) . Collier's work is relevant to the present study because, if secondary school LEP students experience greater 
difficulty with academic work in English than do elementary school students, how much more difficult it must be for LEP students to perform well in American colleges and universities. If secondary school students need from 6 to 8 years to reach norm levels, post-secondary students must require at least as long, if not longer. Any discussion of the academic success of ESI students should take this into consideration.

While the studies described above seem to cast doubt on the effectiveness of developmental English programs, some researchers have reported favorable findings. Boggs (1984) studied developmental writing and freshman composition students at Butte college to look at the effect of the developmental writing course (ENG 102) on the academic achievement of students. While these were not identified as ESI students, they were people whose English skills were not good enough to admit them to the regular freshman composition classes.

Boggs examined the transcripts of 3,497 students and found that completion of ENG 102 prior to enrolling in ENG 210 had a significant impact on student achievement and persistence. Despite scoring lower on every measure of prior English language ability, these students were able to complete ENG 210 at a rate not significantly different from those placed directly into ENG 210. Furthermore, Boggs found that the positive impact of ENG 102 continued 
throughout the students' time at Butte college. The students in the developmental group were able to complete more credit hours during the quarter they were enrolled in ENG 210 than other students, they completed substantially more units while at the college, and they achieved a significantly higher grade point average. Boggs concludes that ENG 102 helped these students to achieve in college despite their prior language difficulties.

In a similar study kolzow (1986) gathered data on the college careers of native English-speaking students who took preparatory reading and communications courses at william Rainey Harper College. He found that the grades students received in the remedial courses correlated very closely with the grades they received in other courses. This was especially true of the developmental reading course. Kolzow's findings lend support to those of Johns and Ostler, who found reading to be the most important skill for academic success. Kolzow also stated that an extremely interesting finding was the extent to which students who did well in the remedial communications course went on to take English courses and do well in them. Kolzow concluded that the developmental courses were valuable to the students and continued to help them throughout their college careers. While this may well be the case, he failed to point out that the students who did well in the preparatory classes may have had better study skills, greater motivation, or some 
other attribute that caused them to be more successful than those who did poorly in such courses.

However, another study supports Kolzow's findings by also showing a significant correlation between success in reading and writing courses and academic persistence. Kangas and Reichelderfer (1987) studied the persistence of entering students at Evergreen Valley College. The students were divided into these groups: English students, ESL students, and students who took no placement test and no English or ESL reading or writing courses within their first two semesters. The English and ESL students were further divided as follows: "remedial," "non-remedial," and those who qualified for English or ESL but did not take either. Finally, the "remedial" and "non-remedial" groups were divided into those who were successful and nonsuccessful in their first English or ESL classes. The persistence of each group over four semesters was tracked and the groups were compared.

Kangas and Reichelderfer reported eight major findings from this research. (1) one of the most significant factors related to persistence was success in reading or writing. Seven of the eight highest persisting groups had successful initial experiences in English or ESI reading or writing classes. (2) Students who successfully completed both English reading and writing persisted at a higher rate than those who took only reading or writing.

(3) One of the most 
significant factors related to low persistence was nonsuccess in reading and/or writing classes.

Nonsuccess had more impact on the persistence of "remedial" students than on that of "nonremedial" students.

(5) A high degree of personal/cultural support for educational goals seemed to be related to persistence. Ninety-one percent of the ESL group had Asian surnames compared to twelve percent of the English group. The researchers assumed that this cultural group had high support for educational goals. The top three groups in persistence were ESL groups.

"Remedial" students persisted as well as "nonremedial" students when they had success or high support for educational goals. (7) Students who took no placement test and no English or ESL reading or writing courses had one of the lowest rates of persistence of all the groups, eleven percent at the end of the fourth semester. (8) Students who qualified for, but did not take, the English or ESL reading and writing courses did not persist as well as those who took them.

Kangas and Reichelderfer's findings indicate that remedial English and ESL programs can have a significant effect on the academic success of students. Their results contradict those of Mason, Mosback, and Brown discussed earlier. It can be seen that there is no consensus among researchers as to the effectiveness of developmental English programs. Graham (1987) stated that in the face of 
contradicting results, the ESL professional should attempt to find the minimum level of English proficiency required for success at the particular institution. One way to do this is to monitor the academic achievement of students with limited English skills. She also noted that visiting international students and limited-English-speaking residents or immigrants may be two distinctly different groups in terms of background and characteristics. She indicated that little work has been done on these differences, except for a few studies that seem to show differences in the effectiveness of certain language tests for the two groups.

This review of literature leads to three conclusions relevant to my research. (1) Faculty and students seem to agree that the language skill most necessary to academic success is reading. (2) GPA can be used as one measure of academic success but it should be accompanied by other measures which compensate for the variability of the courses upon which GPA is based. (3) Studies conducted to evaluate the success of ESL and developmental English programs have produced varied results, making more such studies necessary for the development of effective programs. 


\title{
CHAPTER III
}

\section{METHODS AND PROCEDURES}

\author{
SUBJECTS
}

The subjects in this study consisted of four groups of ENNR students and a control group. The ENNR students were selected for the ENNR program based on a series of placement tests. They were given the Michigan Test of English Language Proficiency, the Comprehensive English Language Test for Speakers of English as a Second Language (CELT), and a writing test consisting of two writing samples. These tests were used to determine eligibility for the program and placement in the three levels (Intermediate 1, Intermediate 2, and Advanced). Students who scored 85-95 on the Michigan Test, 90-100 on the CELT, or whose writing samples showed superior English ability were exempted from the program. Thus, in 1984 for example, fourteen students were exempted by testing. It should be noted here that at about the time the ENNR program was started, there was an influx of recent immigrants from Vietnam to the Portland area. Many of the students who were placed in ENNR came from this group. Their English skills were quite low, their schooling had been interrupted by time spent in refugee camps, and many 
were affected by personal and family trauma.

For the purposes of this study, the ENNR students were subdivided into groups according to the year in which they originally enrolled in PSU. Thus, there were groups for 1984, 1985, 1986, and 1987. These groups were identified for the purposes of this study by the last digit of those years. Their academic records were obtained from the office of the Registrar at PSU by requesting the cumulative records of all students enrolled in the ENNR program in the fall term of each of the four years.

After these records were received, a few of the students were eliminated from the study because of anomalies in their academic records that would cause the data for their groups to be skewed. Some students entered the University as early as ten years before the other students and, after enrolling for several terms, left for a period of time, then returned and enrolled in the ENNR program during one of the target years of the study. The work done before participation in the ENNR program could not be included in the study because it could not have been affected by the program. Therefore, the GPA, number of average credit hours per term, and graduation of these students would have adversely affected the validity of the data for their groups. There were also several students who never actually completed any ENNR classes but who apparently were considered to be enrolled in the program. They too were 
taken out of the study.

The control group for the study was selected for their similarity to the ENNR students on two important criteria. 1) Their native language was not English, and 2) their English skills were not considered adequate for successful academic work at PSU. These students entered PSU from 1982 to 1985 and were enrolled in a preparatory writing course, WR 199A, based on a TSWE score of less than 34-35, a TOEFL score of less than 525, teacher recommendation, or self-referral.

WR 199A was a class designed to help students who were not prepared to take the Ireshman composition course, WR 121. It generally concentrated on units smaller than the essay, teaching usage and mechanics, sentence combining, and paragraph logic and construction. The students in WR $199 \mathrm{~A}$ were both non-native English speakers and native English speakers. (Native English speakers were not part of the control group.) The non-native English speaking students could not enroll in the ENNR program because it did not exist before 1984 and because for the most part these students were international students, not non-native residents. Information on the backgrounds of the WR 199A students is sparse. As mentioned above, some were self-selected for this class and could have succeeded in WR 121 without it. We do not know how much ESI these students had taken before entering PSU. If given the same tests as 
the ENNR students, some of them might have scored as high as those who were exempted from ENNR. The implications of these factors will be discussed in Chapter v.

The academic records of the non-native English speaking WR 199A students were obtained from the office of the Registrar. Upon examination, several of these students were found to have later enrolled in the ENNR program; therefore, those particular students were eliminated from the study. The control group was identified in the study as Group 1 .

After all ineligible students were taken out of the subject groups, the remaining numbers were as follows:

\begin{tabular}{|c|c|c|}
\hline up & (control) & \\
\hline oup & $(1984)$ & \\
\hline up & $(1985)$ & - \\
\hline Group & $(1986)$ & 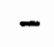 \\
\hline p & (1987) & \\
\hline
\end{tabular}

ANALYSIS OF THE DATA

The following data were collected and recorded for each subject:

Cumulative GPA: The figure used for this measure was that calculated by the office of the Registrar and recorded on each transcript.

Total credit hours earned: This figure was also calculated by the Registrar. However, transfer hours were subtracted from the total, since for the purposes of this study, they were not relevant and since there was no information regarding what kind of classes they were. 
Number of terms of enrollment at PSU: This figure was obtained by counting the number of terms shown on the transcripts.

Grades in WR 121, WR 323 and ENNR Grammar Workshop: Grades were taken directly from the transcripts. For the purposes of statistical analysis, the grades were coded as follows: $A=4, B=3, C=2, D=1, F=0$. Some students chose the Pass/No Pass grade option. In those cases, Pass (P) was coded as 2. (Work that does not merit a $C$ grade is not considered by PSU as passing for P/NP courses.) No Pass (NP) was coded 0 .

Credit hours attempted in courses requiring more reading and credit hours with grade $C$ or better in courses requiring more reading: Since it was impossible for the researcher to survey each faculty member at PSU regarding the amount of reading required in his/her courses, and since variation can occur from term to term and year to year for individual professors, the determination of which courses require more reading than others became a rather subjective operation. In general, courses in the humanities, social science, and general science were counted in this measure. Courses in engineering, art (with the exception of art historyl, math, accounting, computer science, and foreign languages (other than English) were not counted. While the decision as to whether or not to include particular courses can be debated, the researcher was careful to remain 
consistent once such decisions had been made. In order to check such decisions against objective information, a survey of the textbooks required for the different disciplines was made in the PSU Bookstore. The survey generally confirmed judgments made about the comparative amount of reading required for different subjects.

Hours in classes requiring more reading were counted as attempted if the student received a grade $A$ through $F$ for NP). They were counted as having a grade $\mathrm{C}$ or better if the student received $A$ through $C$ (or $P$ ).

Last term attended: The last term the student was enrolled at PSU was recorded in order to determine if the student was still pursuing a degree. Since the academic records used were cumulative through fall term of 1989, if the student was enrolled in fall 1989, he/she was considered to be active.

Degree received: Degrees received were taken directly from the Registrar's information provided on the transcripts.

Academic disqualification: Academic disqualifications were taken directly from the Registrar's information provided on the transcripts.

Although the researcher would have been interested in knowing the students' majors, this information is not recorded on the transcripts and could not be determined for many of the students by looking at their choice of classes. 
Therefore, academic majors could not be considered in analyzing the other data.

The data gathered by the means described above were analyzed in various ways in order to test the four hypotheses. The following is a reiteration of each hypothesis and a description of the procedures used.

Hypothesis 1. Enrollment in the ENNR program has a positive effect on academic performance at PSU, as measured by significantly higher cumulative grade point averages, higher total credit hours earned, higher number of credit hours earned per term of enrollment, fewer students being academically disqualified, and more students receiving a bachelor's degree after at least four years of study, among ENNR students as compared to the control group.

To test this hypothesis, the mean GPAs of all groups were compared using Analysis of Variance (ANOVA) to determine if the differences were statistically significant. The mean credit hours per term for all groups were also compared using ANOVA, as were the mean total credit hours for the groups who enrolled before 1986 (groups 1,4, and 5), since those groups would have had sufficient time to complete a four-year program. The nominal data for number of $\mathrm{Ss}$ in all groups who were academically disqualified were compared, and the number in groups 1,4, and 5 who received degrees were compared, using the Fisher Exact Test. This test was used instead of chi-square when any of the expected 
frequencies were less than 5 .

Hypothesis 2. Enrollment in the ENNR program has a positive effect on performance in WR 121 and WR 323, as measured by a significantly higher number of ENNR students receiving at least a C grade in WR 121 and WR 323 as compared to the control group.

For this hypothesis, the number of $S s$ in groups $4,5,6$, and 7 who earned a C (or P) or better in WR 121 was compared to those in group 1. Also, the number of Ss in groups $4,5,6$, and 7 who earned a D, F, or NP in WR 121 was compared to those in group 1. The groups were additionally compared for the number of students who had to repeat WR 121. These nominal data were analyzed using the Fisher Exact Test. This procedure was repeated for the grades in WR 323.

Hypothesis 3: Enrollment in the ENNR grammar workshop has a positive effect on performance in WR 121, as measured by a significantly higher number of grammar workshop participants receiving at least a C grade in WR 121 as compared to the control group.

For groups $4,5,6$, and 7 , the number of $S s$ who enrolled in the grammar workshop and also received a grade of $C$ or better in WR 121 was compared to the number of Ss meeting these criteria in group 1, using the Fisher Exact Test.

Hypothesis 4: Enrollment in the ENNR program has a positive effect on performance in academic courses requiring reading (such as social science and humanities) as measured 
by a significantly higher number of credit hours attempted in those subjects per term enrolled and a significantly higher number of credit hours with grades of $\mathrm{C}$ or better in those subjects per term enrolled, among ENNR participants as compared to the control group.

For each measure (credit hours attempted and credit hours earned with grade $C$ or better), groups $4,5,6$, and 7 were compared to group 1 using the Fisher Exact Test.

It should be noted that the comparisons of the different groups on the various measures described above can only be used to determine the degree of difference between the groups and whether that difference is statistically significant. It does not necessarily indicate a cause and effect relationship between the treatment (ENNR) groups and the treatment (the ENNR program). For this study, the significance level (P) was set at .05. That is, $P$ must be less than or equal to .05 in order for the difference between the compared groups to be considered greater than expected for any unrelated groups. A significance level of .05 allows generalizations to be made from a small sample. 


\section{CHAPTER IV}

\section{RESULTS}

\section{ACADEMIC SUCCESS}

The first hypothesis tested in this study was that enrollment in the ENNR program has a positive effect on academic performance at PSU. Academic performance was measured by comparing mean cumulative grade point averages, mean total credit hours, mean number of credit hours earned per term of enrollment, number of students who were academically disqualified, and number of students who received a bachelor's degree after at least four years of potential study, among the five groups. Group 1 consisted of students who were not enrolled in the ENNR program, but who instead were enrolled in a developmental writing course. They served as the control group. Groups $4,5,6$, and 7 were students enrolled in the ENNR program in the years 1984, 1985,1986 , and 1987 respectively.

Data for the first measure, cumulative GPA, is shown in Table I. 
TABLE I

CUMULATIVE GPAS

\begin{tabular}{cccccc} 
Group & N & $\begin{array}{c}\text { Minimum } \\
\text { GPA }\end{array}$ & $\begin{array}{c}\text { Maximum } \\
\text { GPA }\end{array}$ & $\begin{array}{l}\text { Mean } \\
\text { GPA }\end{array}$ & $\begin{array}{l}\text { Standard } \\
\text { Deviation }\end{array}$ \\
\hline 1 & 46 & 1.760 & 3.830 & 2.633 & 0.562 \\
4 & 52 & 1.090 & 4.000 & 2.690 & 0.621 \\
5 & 52 & 0.000 & 4.000 & 2.416 & 0.793 \\
6 & 62 & 0.850 & 4.000 & 2.389 & 0.700 \\
7 & 62 & 0.000 & 4.000 & 2.439 & 0.818
\end{tabular}

The mean cumulative GPAs for all five groups were compared using one-way Analysis of Variance (ANOVA) with the significance level set at .05. The significance found for this comparison was .096, too high to disprove the null hypothesis. In other words, the differences between the groups are not significant on this measure. Table II shows the results of the ANOVA.

TABLE II

ANOVA FOR CUMULATIVE GPA

\begin{tabular}{lrrrrr} 
Source & SS & df & MS & F & P \\
\hline Between groups & 4.048 & 4 & 1.012 & 1.993 & 0.096 \\
Within groups & 136.624 & 269 & 0.508 & &
\end{tabular}

Mean credit hours earned per term were the next data examined. Table III shows these data. 
TABLE III

CREDIT HOURS EARNED PER TERM OF ENROLLMENT

$\begin{array}{cccccc}\text { Group } & N & \begin{array}{l}\text { Minimum } \\ \text { Cr.Hrs. }\end{array} & \begin{array}{l}\text { Maximum } \\ \text { Cr.Hrs. }\end{array} & \begin{array}{l}\text { Mean } \\ \text { Cr.Hrs. }\end{array} & \begin{array}{l}\text { Standard } \\ \text { Deviation }\end{array} \\ 1 & 46 & 3.500 & 18.000 & 10.515 & 3.317 \\ 4 & 52 & 5.667 & 15.929 & 11.427 & 2.321 \\ 5 & 52 & 3.143 & 15.250 & 10.632 & 2.692 \\ 6 & 62 & 3.000 & 19.500 & 10.943 & 3.327 \\ 7 & 62 & 3.000 & 16.857 & 11.192 & 3.212\end{array}$

Comparing the mean credit hours per term of all five groups, using ANOVA, did not show a significant difference between the groups. Comparing the mean credit hours per term of groups 4, 5, and 1, using a t-test, also did not reveal significant differences. Tables IV, V, and VI present these data.

TABLE IV

ANOVA FOR MEAN CREDIT HOURS PER TERM

\begin{tabular}{lrrrrr} 
Source & \multicolumn{1}{c}{ SS } & df & MS & F & P \\
Between groups & 29.399 & 4 & 7.350 & 0.809 & 0.520 \\
Within groups & 2444.073 & 269 & 9.086 & &
\end{tabular}

TABLE V

CREDIT HOURS EARNED PER TERM GROUPS 1 \& 4

N Mean SD

$\begin{array}{llll}\text { Group } 1 & 46 & 10.515 & 3.317 \\ \text { Group } 4 & 52 & 11.427 & 2.321\end{array}$

Separate variances: $t=1.558, \mathrm{df}=79.3, \mathrm{p}=.123$ Pooled variances: $t=1.591, d f=96.0, p=.115$ 
TABLE VI

CREDIT HOURS EARNED PER TERM

GROUPS $1 \& 5$

N Mean SD

$\begin{array}{llll}\text { Group } 1 & 46 & 10.515 & 3.317 \\ \text { Group } 5 & 52 & 10.632 & 2.692\end{array}$

Separate variances: $t=.190, \mathrm{df}=86.7, \mathrm{p}=.850$

Pooled variances: $t=.193, d f=96.0, p=.848$

Next, the number of $S s$ in all groups who were academically disqualified at some point in their careers at PSU were compared using the Fisher Exact Test since the expected frequencies were five or less. The raw data are shown in Table VII.

\section{TABLE VII}

NUMBER ACADEMICALLY DISQUALIFIED

Academic

Disqualifications $\mathrm{N}$

Group 1

Groups 4-7

5

22

46

228

An analysis using the Fisher Exact Test resulted in a nonsignificant difference $(P=.4)$ between the groups for this measure. There were not a significantly different number of academic disqualifications among the ENNR groups as compared to the control group.

Finally, the number of $\mathrm{Ss}$ who received bachelor's degrees after at least four years of potential study were compared for groups 1, 4, and 5. (Groups 6 and 7 enrolled 
at PSU for the first time too recently to have earned bachelor's degrees at this point.) These data are shown in Table VIII.

\section{TABLE VIII}

\section{BACHELOR'S DEGREES EARNED}

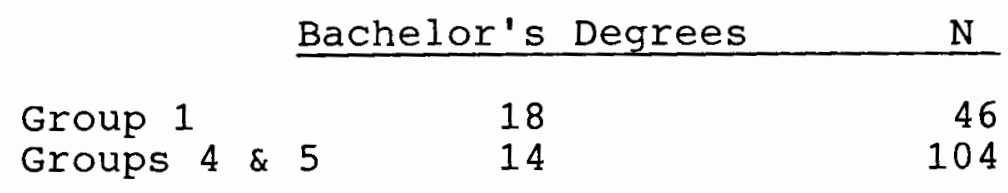

The data on bachelor's degrees earned were analyzed using chi-square. This yielded a value for chi-square of 7.72, which is greater than the value needed to reject the null hypothesis (3.84). Thus, the control group earned a significantly higher number of bachelor's degrees than did the ENNR groups.

PERFORMANCE IN WR 121 AND WR 323

Hypothesis 2 states that enroliment in the ENNR program has a positive effect on performance in WR 121 and WR 323 . To test this, data were gathered on subjects' performance in those two classes. These data appear in Table IX.

\section{TABLE IX}

GRADES IN WR 121 AND WR 323

\begin{tabular}{|c|c|c|c|c|c|c|}
\hline & $\begin{array}{l}\text { Grades } \\
A-C\end{array}$ & $\begin{array}{l}\text { Grades } \\
D-F\end{array}$ & $\mathrm{~N}$ & $\begin{array}{l}\text { Grades } \\
A-C\end{array}$ & $\begin{array}{l}\text { Grades } \\
D-F\end{array}$ & \\
\hline roup & WR 121 & WR 121 & WR 121 & WR 323 & WR 323 & WR 32 \\
\hline $\begin{array}{l}1 \\
4-7\end{array}$ & $\begin{array}{r}31 \\
116\end{array}$ & $\begin{array}{l}1 \\
8\end{array}$ & $\begin{array}{r}32 \\
124\end{array}$ & $\begin{array}{l}24 \\
59\end{array}$ & $\begin{array}{l}1 \\
2\end{array}$ & $\begin{array}{l}25 \\
61\end{array}$ \\
\hline
\end{tabular}


The Fisher Exact Test was used to compare the groups and the difference between them was found to be nonsignificant $(\mathrm{P}=.30$ for $\mathrm{WR} 121$ and .18 for WR 323$)$.

Some students found it necessary to repeat either WR 121 or WR 323 in order to achieve a passing grade. All five groups were compared on this factor also, as shown in Table $\mathrm{x}$.

TABLE $X$

NUMBER OF SUBJECTS WHO REPEATED WR 121 OR WR 323

\begin{tabular}{lcccc} 
Repeat & N & Repeat & N \\
WR 121 WR 121 & WR 323 & WR 323 \\
\hline
\end{tabular}

$\begin{array}{lrrrr}\text { Group } 1 & 6 & 32 & 3 & 25 \\ \begin{array}{l}\text { Groups } \\ 4-7\end{array} & 12 & 124 & 1 & 61\end{array}$

While the differences in the raw data for between group 1 and groups 4-7 look substantial, the Fisher Exact Test yielded significance levels of .13 for subjects repeating WR 121 and .07 for those repeating WR 323, again not significant differences. The sample number is simply too small to show that the differences could not have been caused by chance.

THE EFEECT OF THE ENNR GRAMMAR WORKSHOP

It was hypothesized that the grammar workshop would have a positive effect on performance in WR 121, as measured by a significantly greater proportion of grammar workshop participants receiving at least a C grade in WR 121 as 
compared to the control group. The data shown in Table XI were used to test the hypothesis.

\section{TABLE XI}

PERFORMANCE IN WR 121 OF GRAMMAR WORKSHOP PARTICIPANTS

Grade $C$ or Better Total Enrolled

Group 1

Grammar Workshop

Participants
31

12
32

13

The Fisher Exact Test did not show a significant difference between these two groups on this measure.

PERFORMANCE IN COURSES REQUIRING MORE READING

Hypothesis 4 states that the ENNR program has a positive effect on performance in academic courses requiring comparatively more reading, as measured by a significantly higher number of credit hours attempted in those subjects per term enrolled and a significantly higher number of credit hours with grades of $C$ or better in those subjects per term enrolled, among ENNR participants as compared to the control group. The data for these measures are shown in Tables XII through XV. 


\section{TABLE XII}

CREDITS IN COURSES REQUIRING READING, PER TERM ENROLLED

\begin{tabular}{lllrll} 
Group & N & $\begin{array}{c}\text { Minimum } \\
\text { Credits }\end{array}$ & $\begin{array}{c}\text { Maximum } \\
\text { Credits }\end{array}$ & Mean & $\begin{array}{l}\text { Standard } \\
\text { Deviation }\end{array}$ \\
\hline 1 & 46 & 0.000 & 11.077 & 3.278 & 2.341 \\
4 & 52 & 0.000 & 9.714 & 3.378 & 2.085 \\
5 & 52 & 0.000 & 8.250 & 2.882 & 2.162 \\
6 & 62 & 0.000 & 11.500 & 3.350 & 2.243 \\
7 & 62 & 0.000 & 7.750 & 3.200 & 2.211
\end{tabular}

Mean credit hours in courses requiring more reading per term enrolled were compared using ANOVA. This yielded a significance level of .78 . That is, differences among the groups were not statistically significant. This is shown in Table XIII.

TABLE XIII

ANOVA FOR MEAN CREDIT HOURS REQUIRING READING

Source

Between groups

Within groups SS

$\begin{array}{rrr}8.47 & 4 & 2.12 \\ 1311.91 & 269 & 4.88\end{array}$

Mean credit hours with grades of $\mathrm{C}$ or better in these classes were also compared using ANOVA, with similar results. The significance level was .50 . These data are displayed in Tables XIV and XV. 
TABLE XIV

CREDITS WITH GRADE C OR BETTER IN COURSES REQUIRING READING, PER TERM ENROLLED

Group N $\quad \begin{aligned} & \text { Minimum Maximum } \\ & \text { Credits }\end{aligned}$ Credits Mean $\quad \begin{aligned} & \text { Standard } \\ & \text { Deviation }\end{aligned}$

$\begin{array}{rrrrrr}1 & 46 & 0.000 & 8.385 & 2.700 & 1.856 \\ 4 & 52 & 0.000 & 9.714 & 3.140 & 1.976 \\ 5 & 52 & 0.000 & 6.385 & 2.455 & 1.926 \\ 6 & 62 & 0.000 & 11.500 & 2.562 & 2.146 \\ 7 & 62 & 0.000 & 7.429 & 2.575 & 2.099\end{array}$

TABLE XV

ANOVA FOR CREDITS WITH GRADE C OR BETTER IN COURSES REQUIRING READING, PER TERM ENROLLED

Source

Between groups

Within groups
SS

$\begin{array}{rr}13.68 & 4 \\ 1065.76 & 262\end{array}$

\begin{abstract}
MS
\end{abstract}
3.42

4.07

F P

Thus, the data for credit hours attempted in courses requiring more reading and credit hours with grade $c$ or better in those courses were not significantly different for the groups. As a result, these data do not support Hypothesis 4 .

\section{SUMMARY OF FINDINGS}

A significant difference between the control group and the ENNR groups was found on only one of the measures in this study: the control group earned a significantly higher number of bachelor's degrees than did the ENNR groups.

On all other criteria examined, the differences between the groups were shown to be non-significant. Thus, the data do 
not support any of the hypotheses that this study was designed to test. 


\section{CHAPTER V}

\section{CONCLUSION AND DISCUSSION}

Although the ENNR program at PSU has been in operation for nearly five years, no study of this type had been done to measure its effectiveness. A program evaluation was done in 1986 with a grant from the Committee on Effective Education. I attempted to locate a copy of that study but was unable to find one. Because there is so little information on the effect of the ENNR program, the present study was undertaken to examine the academic records of ENNR students and compare them to a control group in order to determine whether the ENNR program was having a positive effect on the students' studies at PSU. Four hypotheses were set forth to be tested and data were gathered from student transcripts provided by the office of the Registrar. The data were analyzed using three statistical tests: Analysis of Variance for comparing means, and chi-square and the Fisher Exact Test for comparing nominal data. The following is a brief restatement of each hypothesis and the conclusions that can be drawn from the data.

Hypothesis 1: Enrollment in the ENNR program has a positive effect on academic performance at PSU, as measured by significantly higher cumulative grade point averages, 
higher total credit hours earned, higher number of credit hours earned per term of enrollment, fewer students being academically disqualified, and more students receiving a bachelor's degree after at least four years of study, among ENNR students as compared to the control group. As stated in Chapter IV, no significant differences were found among the groups for cumulative GPA, total credit hours earned, credit hours earned per term of enrollment, or number of academic disqualifications. A significant difference was found in the number of students who earned bachelor's degrees; significantly more control group students earned bachelor's degrees. As a result, it must be concluded that this research does not support Hypothesis 1.

Hypothesis 2: Enrollment in the ENNR program has a positive effect on performance in WR 121 and WR 323, as measured by a significantly higher number of ENNR students receiving at least a C grade in WR 121 and WR 323, as compared to the control group. Again, no significant differences were found between the groups. These results do not support Hypothesis 2 .

Hypothesis 3: Enrollment in the ENNR grammar workshop has a positive effect on performance in WR 121, as measured by a significantly higher number of grammar workshop participants receiving at least a C grade in WR 121 as compared to the control group. No significant difference was found between the groups in regard to grades in WR 121 . 
This result does not support Hypothesis 3 .

Hypothesis 4: Enrollment in the ENNR program has a positive effect on performance in academic courses requiring reading (such as social science and humanities) as measured by a significantly higher number of credit hours attempted in those subjects per term enrolled and a significantly higher number of credit hours with grades of $\mathrm{C}$ or better in those subjects per term enrolled, among ENNR participants as compared to the control group. Once again, when the data were analyzed, no significant differences were found. Therefore, this study does not support Hypothesis 4.

In short, none of the hypotheses was supported by the data. What does this mean? Is the ENNR program ineffective in helping students prepare for academic classes at PSU? This researcher does not leap to such a conclusion. While none of the data showed the ENNR students' academic performance to be superior to that of the control group, there are limiting factors that should be considered in drawing conclusions from this study.

\section{LIMITATIONS}

The control group presents the major limitation of this research. The WR 199A students provided the closest match to the ENNR students that could be found among non-ENNR participants who were not enrolled in an ESI program. That is, they were non-native English speakers whose English 
skill levels were generally considered inadequate for success in WR 121, as measured by TOEFL or TSWE results, or faculty perception. However, like the ENNR groups, they were not selected randomly and beyond the criteria mentioned above little information is available about them. It is not known, for instance, whether the length of time they had been in the United States was comparable to that of the ENNR students or whether the difficulties they experienced with academic classes in English were truly the same as those of the ENNR students. We do not know at what point in their lives they began their study of English and, as Collier (1987 and 1989) concluded, students who learn a second language as teenagers take longer to reach proficiency than do younger children. Since the ENNR students were mostly refugees, they may have learned their English later in life than the WR 199A students. In addition, the control group may not have had the problems experienced by refugees, including interrupted schooling, time spent in refugee camps, relocation trauma, and having to leave family members behind. If most of the control group subjects did not experience these difficulties, they were already ahead of the ENNR students.

Furthermore, while many of the control subjects were placed in WR 199A by test results showing a need for better English skills, according to instructors some of them enrolled in WR 199A for reasons of their own, such as 
needing three more credits or because they thought it would be an easy class. As a result, it is quite possible that the average level of English ability in the control group was much higher than that of the ENNR groups. After all, the ENNR students were placed in the ENNR program precisely because their English skills were so low that their academic success was threatened. In fact, the director of the ENNR program at the time these students were enrolled, Dr.

Jeannette DeCarrico, reports that once the ENNR program was in place, Portland state began admitting more non-native resident students whose English proficiency was borderline, with the requirement that they enroll in the program. Thus, the control group was not as close a match with the ENNR group as one would have liked.

Unfortunately, a more closely matched control group does not exist at PSU. ESL students cannot be used as a control because the ESL classes they take would make a Comparison with ENNR students invalid. Non-native English speaking students not enrolled in any English program cannot be used either; if their English were comparable to that of the ENNR students, they would be enrolled in some type of developmental English class. The fact that they are not shows their English to be sufficient for other academic work. Therefore, the WR 199A students were accepted as the best control group available at PSU. The findings of this study must be interpreted in the light of the possibly 
superior English skills the control group may have possessed. This will be discussed further in the Conclusions and Implications section below.

Additional limiting factors are found in the ENNR groups. Actual enrollment in ENNR classes varied quite widely among these students. Some completed the entire program. Others took only one or two ENNR classes and then proceeded with a regular academic program. A few students took one or two ENNR classes and then never enrolled again at PSU. While this may indicate their perception that the ENNR classes did not prepare them adequately for other courses, it could also be that family or financial situations caused them to stop attending school. Thus, they not only lowered the figures for total credit hours, but they did not contribute potential positive data for such measures as credit hours earned per term of enrollment, cumulative GPA, grades in WR 121 and WR 323, and bachelor's degrees received.

Another limitation of this study was the sample size. While the total number of ENNR students was 228 , the control group was only 46 subjects. It must be remembered that the smaller the sample, the less significant any differences among groups will be. There was no way to increase the size of these groups, since they were not drawn randomly from the student population, but consisted of the entire enrollment in the ENNR program for 1984, 1985, 1986, and 1987 and a 
control group that was drawn from enrollment in a particular developmental writing course.

One further limitation is the question of what other factors besides language ability are involved in academic success. The results obtained by this study serve to illustrate a point raised by Saltzer (1982). He notes that numerous factors in academic success or failure are not related to language proficiency and he states that these factors make any attempt to draw conclusions about the success of ESL programs from the academic records of participants suspect (pp. 91-92).

In order to overcome some of the limitations of the present study and obtain more valid results, the sample size would need to be increased substantially. Unfortunately, the only way to do that for the ENNR groups is to wait for more students to complete the program and progress toward their degrees. This would mean continuing the program for several more years before attempting another evaluation. The expansion of the control group presents a major problem. Now that the ENNR program is in place, all students who meet the criteria for the program are enrolled in it and thus become ineligible to be part of a comparison group. It might be possible to compare the ENNR program to another type of student, such as ESL students, or the general student population of PSU. However, such comparisons would not answer the fundamental question that the present study 
attempted to answer: Does participation in the ENNR program have a positive effect on the particular type of student it serves? Comparisons with other types of students would not tell us how ENNR-eligible students would have performed without the ENNR program.

Another possible avenue of research would be to compare the academic records of ENNR students to those of participants in similar programs at other institutions. Such a study would give researchers an idea of how well the ENNR program is succeeding compared to others. However, differences between the institutions themselves might make it hard to draw conclusions from such a comparison.

\section{IMPLICATIONS}

As stated at the end of Chapter IV, a significant difference between the control group and the ENNR groups was found on only one measure in this study. The control group earned significantly more bachelor's degrees after at least four years of study than the ENNR students. On all other measures the ENNR students were virtually no different than the control group students. While these results do not support any of the hypotheses set forth in this study, the characteristics of the groups involved allow a very interesting interpretation of the data. Considering that the ENNR students were placed in the program because of serious deficiencies in their English skills, that they were 
mostly refugees with many other potential problems that could interfere with academic success, and considering that the control group was most likely superior to the ENNR students in English ability and may not have had as many non-academic problems, it seems quite remarkable that no significant differences were found between the groups on eight out of nine measures.

In fact, a group of students who faced many disadvantages in competing at PSU was able to achieve a level of success comparable to that of students we must consider to have been relatively advantaged. The ENNR students earned comparable GPAs, comparable credit hours per term, and similar grades in WR 121 and 323. Even the least English-proficient students, those required to take the grammar workshop, earned grades in WR 121 comparable to the control group. The groups enrolled in a similar number of classes requiring relatively more reading and achieved similar grades in them. This is particularly interesting because the ENNR students were limited to fifteen credit hours per term of such classes while enrolled in the ENNR program. The control group was not limited in this way. The ENNR students were disqualified no more frequently than the control students. I originally hypothesized that the ENNR students would show superiority over the control group and that such results would indicate that the ENNR program was helping them to succeed at PSU. In light of the 
inherent differences between the ENNR group and the control group, some of which I only became aware of after my research had been completed, it now seems that by achieving at the same level as the control group, the ENNR students may have shown the improvement in their skills that the ENNR program was designed to achieve.

Before discussing the implications of this, I would like to consider the one measure for which a significant difference was found, the number of bachelor's degrees earned by the two groups. Out of 46 students in the control group, 18 (398) had earned bachelor's degrees by the winter of 1990. Out of 104 students in ENNR groups 4 and 5 (those who enrolled at least four years ago), 14 (13\%) had earned bachelor's degrees. As noted earlier, some members of the control group entered the university as early as 1982 and therefore had a longer period of time in which to earn a degree. The ENNR students did not enroll before 1984 .

While the graduation rate among ENNR students may seem low, it is not appropriate to interpret this finding without gaining a larger perspective. One might assume upon casual consideration of the question, that most students complete a bachelor's degree within four years. However, a recent report published by the Oregon state System of Higher Education (1990), shows this not to be the case. Their report examined the graduation rates of student athletes as compared to other students in oregon and in the country as a 
whole. According to their report, the rate of graduation within four years for public four-year institutions nationwide is only 15.3\%. After six years the graduation rate is $42.7 \%$. The report provides the following statistics regarding graduation rates for freshmen entering oregon institutions during three of the years covered by my study of ENNR students:

\section{TABLE XVI}

GRADUATION RATES FOR FIRST-TIME FRESHMEN

$\cdot 84-85$

2.58

3.6

13.08

19.98

$\cdot 85-86$

4.8

14.3

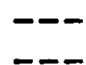

(p. 6)

The report provides an explanation for the length of time needed by students to earn a degree:

...most students take more than four years to complete a bachelor's degree, even at institutions with a more traditional student population such as the University of Oregon and Oregon State University. College costs have risen; students are more dependent on loans and receive less support from parents; more students work while attending school; and the student body has become more diverse and nontraditional. These changes mean a change in the pace at which students complete an undergraduate program of study. (p. 3)

ENNR students are similar to other students in oregon in that they must pay the higher cost of tuition and many must work while attending school. They are dissimilar in that they also face the struggle of doing all of their 
academic work in a foreign language and a foreign culture. In spite of these difficulties, they have managed to attain a $13 \%$ graduation rate after four to five years of school, compared to an average rate of $13.65 \%$ after five years for all Oregon students who entered in 1983-85. When looked at from the larger perspective of how they compare to all oregon students, their graduation rate can only be regarded as an impressive achievement.

One must be careful when drawing implications from this research on ENNR students. In a study such as this, with a small sample, a less than ideally matched control group, and non-random selection of subjects, it is quite possible to produce Type II errors, that is to erroneously support the null hypothesis. However, keeping this in mind, one can still find encouragement in the results of this study. Apparently, ENNR students are succeeding at PSU at approximately the same rate as students who are better equipped to handle academic work in English. As noted earlier, it cannot be said that the relationship between the ENNR program and ENNR students' success is one of cause and effect. This research has only shown that they may be related.

Also, it is impossible to say which aspect of the program is helping students. While instruction in reading, listening, note-taking, and grammar may indeed give students the skills they need for the PSU classroom, it may also be 
true that the academic advising they receive, the security of having some classes with their peers, and the extra attention they receive from ENNR staff may be the deciding factors in their ability to compete with other students. Participating in the ENNR program may give recent immigrants the time needed to adjust to a new environment before taking full programs of courses with native English speaking students and with instructors who are not sensitive to their unique problems.

More research is needed into the problems and successes of ENNR students. If a more appropriate control group could be identified, it would be valuable to do an analysis of ENNR student academic records on a bi-annual basis, for example. Even without a control group, a tracking process of students who finish the program might provide an awareness of their strengths and weaknesses that could be useful in program development. This present study is only a first step. While there were many confounding variables in this research, I feel that my results are encouraging. ENNR students seem to be achieving more academically than might be expected, given their backgrounds and English skill levels upon enrolling in PSU. While I cannot say that the ENNR program is the direct cause of their success, I believe my research shows that it is an important factor and that it is accomplishing its purpose. 


\section{REFERENCES}

Boggs, George R. 1984. The effect of a developmental writing course on student persistence and achievement: a research report. Butte College, Oroville, CA. (ERIC Reproduction Service, ED 244687 ).

Brown, James Dean. 1980. Newly placed students versus continuing students: comparing proficiency. In on TESOL ' 80 -- building bridges, Janet Cameron Fisher, et al. (Eds.), 111-119. Washington, D.C.: TESOL.

Christison, Mary Ann and Karl J. Krahnke. 1986. Student perceptions of academic language study. TESOL Quarterly 20: 61-79.

Collier, Virginia P. 1987. Age and rate of acquisition of second language for academic purposes. TESOL Quarterly 21: 617-641.

Collier, Virginia P. 1989. A synthesis of research on academic achievement. TESOL Quarterly 23: 509-531.

Eliason, Melissa D. and Susan Jenkins. 1990. A model for assessing the relationship between language proficiency and academic success. Unpublished manuscript.

Graham, Janet G. 1987. English language proficiency and the prediction of academic success. TESOL Quarterly 21: 505-521.

Heil, D. K. and L. M. Aleamoni. 1974. Assessment of the proficiency in the use and understanding of English by foreign students as measured by the test of English as a foreign language. ERIC Research Report No. 350. (ERIC Document Reproduction Service No. ED 0939481

Ho, D. Y. F. and J. A. Spinks. 1985. Multivariate prediction of academic performance by Hong Kong University students. Contemporary Educational Psychology 10: 249-259.

Johns, Ann M. 1981. Necessary English: a faculty survey. TESOL Quarterly 1551-1557. 
Kangas, Jon Alan and Nancy Reichelderfer. 1987. Persistence by successful and nonsuccessful remedial and nonremedial English and English as a Second Language students: a longitudinal study. San Jose, CA: San Jose/Evergreen Community College District. (ERIC Reproduction Service, ED 289539 ).

Kolzow, Lee C. 1986. Study of academic progress by students at Harper after enrolling in developmental courses. Palatine, IL: William Rainey Harper College Office of Planning and Research. (ERIC Reproduction Service, ED $265914)$.

Martin, G. M. 1971. A model for the cultural and statistical analysis of academic achievement of foreign graduate students at the University of North Carolina at Chapel Hill. Dissertation Abstracts International 32: $2311 \mathrm{~A}$.

Mason, C. 1971. The relevance of intensive training in EFL for university students. Language Learning 21: 197-204.

Mosback, G. F. 1977. Service courses in ESL at university level -- how effective are they? English Language Teaching Journal 31: 313-318.

Oregon State System of Higher Education. 1990. Academic progress of student athletes in the oregon state System of Higher Education: final report. Eugene, Oregon: Office of Administration, Division of Administrative and Information Systems Services, Institutional Research Services.

Ostler, Shirley E. 1980. A survey of academic needs for advanced ESL. TESOL Quarterly 14: 489-502.

Saltzer, Milton G. 1982. The evaluation of an intensive English program. In The administration of intensive English language programs, Ralph Pat Barrett (Ed.), 89-97. Washington, D.C.: National Association for Foreign Student Affairs.

Slark, J. and Bateman, H. 1982. A study of non-native English speakers' academic performance at Santa Ana College. ERIC Document ED 206368 .

Sokari, H. 1981. Predictors of college success among foreign students from various ethnocultural backgrounds. Dissertation Abstracts International 41: 3543A-3544A. (University Microfilms N.81-03, 656) 
Sugimoto, R. A. 1966. The relationship of selected predictive variables to foreign students' achievement at the University of California at Los Angeles.

Dissertation Abstracts 28: 65A. (University Microfilms No. 67-8032) 